\title{
əRadar Applications in Northern Scotland (RAiNS)
}

\author{
Ryan R. NeEly III, ${ }^{\mathrm{a}, \mathrm{b}}$ Louise PARry, ${ }^{\mathrm{c}}$ DAVID Dufton, ${ }^{\mathrm{a}, \mathrm{b}}$ Lindsay BenNetT, ${ }^{\mathrm{a}, \mathrm{b}}$ AND Chris CollieR ${ }^{\mathrm{a}, \mathrm{b}}$

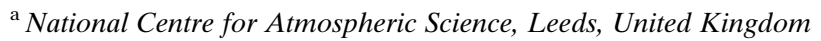 \\ ${ }^{\mathrm{b}}$ School of Earth and Environment, University of Leeds, Leeds, United Kingdom \\ ${ }^{\mathrm{c}}$ Ove Arup and Partners, Leeds, United Kingdom
}

(Manuscript received 16 August 2019, in final form 16 July 2020)

\begin{abstract}
The Radar Applications in Northern Scotland (RAiNS) experiment took place from February to August 2016 near Inverness, Scotland. The campaign was motivated by the need to provide enhanced weather radar observations for hydrological applications for the Inverness region. Here we describe the campaign in detail and observations over the summer period of the campaign that show the improvements that high-resolution polarimetric radar observations may have on quantitative precipitation estimates in this region compared to concurrently generated operational radar quantitative precipitation estimates (QPEs). We further provide suggestions of methods for generating QPE using dual-polarization $\mathrm{X}$-band radars in similar regions.
\end{abstract}

KEYWORDS: Atmosphere; Complex terrain; Precipitation; Rainfall; Hydrometeorology; Radars/Radar observations

\section{Introduction}

Precipitation varies significantly both in time and space. Thus, point-source measurements, such as rain gauges, can only provide limited information of its variability (Ciach and Krajewski 1999; Ciach 2003; Kidd et al. 2017). To overcome these limitations, ground-based Doppler weather radars are routinely used to monitor the spatiotemporal distribution of precipitation in near-real time. Further, with the recent adoption of polarimetric capabilities in operational weather radar networks, the ability to create maps of precipitation on national scales at 5-min frequencies with subkilometer resolutions has become routine. These reveal important microphysical and dynamical information and are an invaluable tool for flood forecasters (Herzegh and Jameson 1992; Zrnić and Ryzhkov 1999; Ogden et al. 2000; Lascaux et al. 2007; Cifelli and Chandrasekar. 2010; Gourley et al. 2010; Berne and Krajewski 2013; Antonini et al. 2017).

The effectiveness of dual-polarization radar for quantitative precipitation estimation (QPE) is demonstrated in numerous previous studies (Matrosov et al. 2005; Bouilloud et al. 2010; Wang and Chandrasekar 2010; Cifelli and Chandrasekar 2010; Cifelli et al. 2011; Diederich et al. 2015a,b; and many others). Most significantly, polarimetric observations have been shown to vastly improve the quality of radar observations used as input to rainfall estimators (Giuli et al. 1991; Ryzhkov and Zrnić 1998; Hubbert et al. 2009; Rico-Ramirez and Cluckie 2008; Kumjian 2013; Lakshmanan et al. 2014; Dufton and Collier 2015). These improvements in quality include better separation of meteorological and nonmeteorological observations as well as improving the calibration of the observations, accounting for partial beam

¿ Denotes content that is immediately available upon publication as open access.

Corresponding author: Ryan R. Neely III, ryan.neely@ncas.ac.uk blockage (PBB) and attenuation (Shakti et al. 2013; Ryzhkov et al. 2014; Diederich et al. 2015a,b). Beam blockage occurs when viewing angle of the radar is obscured by terrain or other obstacles, such as buildings and trees, which are collectively referred to as ground clutter. Blockages significantly limit radar coverage and introduce large biases in radar measurements. When the radar beam is blocked in its entirety, no observations can be made but dual-polarization observations make it possible to account for PBB. Similarly, attenuation of the radar signal can be better quantified by dual-polarization radars.

Beyond improvements to the quality of the observations used as input, rainfall retrievals using combinations of reflectivity $Z_{H}$, differential reflectivity $Z_{\mathrm{DR}}$, and specific differential phase $K_{\mathrm{dp}}$ have advantages over traditional reflectivity-rainfall $(Z-R)$ relations [i.e., Marshall-Palmer (MP)] because more information is available to accurately describe the drop size distribution (DSD) (Marshall et al. 1955; Brandes et al. 2001; Cifelli et al. 2011; Tabary et al. 2011; Diederich et al. 2015b). Dual-polarization radars can also better identify and account for the presence of ice in the sampling volume, which may bias QPEs (Herzegh and Jameson 1992; Fabry and Zawadzki 1995; Straka et al. 2000; Liu and Chandrasekar 2000; Rico-Ramirez et al. 2005; Bechini et al. 2013; Picca et al. 2014; Hall et al. 2015).

An essential issue in dual-polarization radar rainfall estimation is determining which set of polarimetric observables and which method to employ for given meteorological conditions. For example, under what circumstances does $K_{\text {dp }}$ provide information that leads to improved rain estimates relative to methods using $Z_{H}$ alone in an MP relation or in combination with $Z_{\mathrm{DR}}$ ? The answer to this question does not have a singular answer but optimal solutions must exist and will most likely differ regionally.

Here we address this question in the context of the specific circumstances presented by the unique topography and climate of northern Scotland. Mountainous and high northern latitude locations present a unique challenge in making QPEs from 
ground-based radar (Andrieu et al. 1997; Creutin et al. 1997; Germann et al. 2006; Anagnostou et al. 2009, 2010; Vulpiani et al. 2012). Mountainous terrain blocks the radar beam and causes orographic enhancement of precipitation rates, while climatologically low melting bands and shallow precipitation significantly limit the effectiveness of using high elevation scans to observe beyond hills. Thus, the accuracy of QPEs is limited, particularly at far range.

\section{Campaign description and observations}

Scotland has an average annual rainfall of $1570.9 \mathrm{~mm}$ per annum (1981-2010 average; Met Office 2018), but the spatial variability in rainfall totals is high. The variability is predominantly related to the topography of the region with the north and west of Scotland receiving the most rainfall. The topography also poses different challenges to both radar and point measurement methods of observing rainfall (Kendon et al. 2018). Furthermore, the high elevations and low temperatures mean that in winter a significant proportion of precipitation falls as sleet and snow.

The Scottish Environment Protection Agency (SEPA) has a statutory responsibility to provide flood warning across Scotland. SEPA achieves this through an operational partnership with the U.K. Met Office (the Scottish Flood Forecasting Service) by applying meteorological forecasts to a national distributed hydrological model, Grid-to-Grid (G2G), and catchment specific lumped probability distributed models (PDM) (Moore et al. 2006; Bell et al. 2009; Cole and Moore 2009). Both of these model types require precipitation observations as input for model development, calibration, and, operationally, to generate initial conditions for forecasts. For the operational forecasting models, observed precipitation data are provided in near-real time (NRT) from SEPA's network of $\sim 260$ telemetered tipping bucket rain gauges (TBR) and a radar composite generated from four to five Met Office C-band radars (green pentagons in Fig. 1). Both data sources have their strengths and weaknesses, particularly concerning the orography, and therefore spatial representativeness and estimates of rainfall from the two methods can vary widely.

As part of SEPA's Flood Warning Strategy (2012-16), SEPA committed to increasing their understanding of the spatial representation of the real-time measurement of rainfall. Activities associated with this included reviewing the United Kingdom's weather radar network and its suitability for flood warning provision and making recommendations for future improvements to both the radar and point observation network including new or temporary radar installations to help increase the probability of detection. To meet this strategic objective, SEPA partnered with the United Kingdom's National Centre for Atmospheric Science (NCAS) and the University of Leeds' School of Earth and Environment to conduct a pilot study of the use of X-band radar entitled Radar Applications in Northern Scotland (RAiNS).

Operational weather radar data quality over northern Scotland, particularly near Inverness, is reduced due to the location and spacing of radars relative to the mountainous terrain. In addition, orographic enhancement created by the northwestern Highlands



FIG. 1. RAiNS project location: NXPol location (black star), 50and $100-\mathrm{km}$ ranges from the radar (black dashed circles), SEPA TBRs used in the analysis (red triangles), and location of the Met Office operational C-band radars (green pentagons).

and Cairngorms mountain ranges significantly impact local precipitation distributions. The topography of northern Scotland also limits the representivity of the rain gauge network. Previous studies have shown the value of operating a mobile polarimetric $\mathrm{X}$-band radar in such regions to fill gaps in the coverage of national operational radar networks (Matrosov et al. 2005; Wang and Chandrasekar 2010).

In recognition of these issues and previous work, the NCAS mobile X-band dual-polarization Doppler weather radar (NXPol) was deployed at Kinloss Barracks (black cross in Fig. 1), which is home to the 39 Engineer Regiment of the British Army, between February and August 2016 to collect observations to help answer the following two questions:

1) What are the benefits of high temporal and spatial resolution radar precipitation estimates in northern Scotland?

2) Can dual-polarization radar observations improve rainfall estimates used in northern Scotland?

We will explore these questions using the observations from the RAiNS campaign by first examining the advantages of using dual-polarization data processing and QPE methods 
compared to more traditional data processing and QPE methods in this region (section $4 \mathrm{a}$ ). We will then separately examine the dual-polarization methods to further understand what advantages these techniques afford QPEs in this region (section 4b). We will finally compare QPEs derived from the results of the previous section to the Met Office's Nimrod rainfall product to examine question 1 (section $4 \mathrm{c}$ ).

\section{a. NXPol}

The NXPol is a Meteor 50DX manufactured by Leonardo Germany ES GmbH, modified to operate with a larger 2.4-m diameter antenna that produces a $0.98^{\circ}$ half-power beamwidth and without a radome. The radar was deployed on top of a 3-m platform and operated as a semiautonomous observing facility for the duration of the deployment. For more technical details on NXPol and the facility used to support it during the RAiNS deployment, please see Neely et al. (2018). During the RAiNS campaign the scan pattern utilized by NXPol consisted of a set of PPI scans at $0.5^{\circ}, 1^{\circ}, 1.5^{\circ}, 2^{\circ}, 3^{\circ}, 4^{\circ}, 5^{\circ}, 6^{\circ}, 7^{\circ}, 10^{\circ}, 20^{\circ}$, and $30^{\circ}$ (note the highest elevation scan utilized in the QPE in this study is $4^{\circ}$ ) that repeated approximately every $5.5 \mathrm{~min}$. Also included in the repeating volume of scans was an observation at $90^{\circ}$ that is used for calibrating the observed $Z_{\mathrm{DR}}$. All radar observations from NXPol during RAiNS can be found in the Centre for Environmental Data Analysis's (CEDA) Archive (Bennett 2019).

\section{b. Other data sources}

In addition to the data collected by the NXPol we utilize observations from the Met Office's C-band radars and SEPA's network of near-real-time rain gauges (see locations in Fig. 1).

\section{1) Met OfFiCE C-BAND RADARS}

The Met Office operates four C-band radars in Scotland as part of their wider operational network (Darlington et al. 2016). At the time of this study, two of the radars had dualpolarimetric capabilities (the Hill of Dudwick radar located in the northeast and the Holehead radar in the southwest). All radars that are part of the Met Office network have a halfpower beamwidth of $\sim 1^{\circ}$ and typically utilize a $2.0-\mu$ s pulse width with a $300-\mathrm{Hz}$ pulse repetition frequency (PRF) and 300$\mathrm{m}$ range gate length to collect reflectivity measurements whereas Doppler velocity scans utilize a $0.5-\mu$ s pulse width with a $1200-+900-\mathrm{Hz}$ dual-PRF and a $75-\mathrm{m}$ range gate. The higher-resolution scans may also be used to derive highresolution rainfall products within $100 \mathrm{~km}$ of the radar.

All QPE values from the Met Office radars were produced by the Met Office's Nimrod system (Golding 1998). Nimrod is a fully automated system for weather analysis and nowcasting based around a network of $\mathrm{C}$-band rainfall radars. Five scans at different elevations at each site are processed to give the best possible estimate of rainfall at the ground. This processing includes clutter removal, beam blockage and attenuation correction, adjustment for orographic enhancement and bias correction based on observations from the rain gauge network. Rainfall rate estimates were derived from horizontal reflectivity measurements using the MP rain rate relation $(Z=$ $200 R^{1.6}$ ) (Marshall et al. 1955; Harrison et al. 2012). For more information, please see Met Office (2003) and Harrison et al. (2012).

\section{2) RAIN GAUGES}

SEPA's network of near-real-time rain gauges predominantly consists of Campbell Scientific SBS500 tipping-bucket rain gauges (Campbell Scientific Europe 2018). The TBRs have a $0.2-\mathrm{mm}$ tip sensitivity, a $500-\mathrm{cm}^{2}$ collector area, and a maximum recordable rainfall rate of $900 \mathrm{~mm} \mathrm{~h}^{-1}$. The novel aerodynamic shape of the SBS500 increases measurement accuracy and precision compared to traditionally shaped cylindrical gauges, by reducing out-splash and losses caused by evaporation. All data are transferred in near-real time to the SEPA server. Near-real-time data are used by flood forecasting services in conjunction with radar observations and hydrological models. In time the data are further checked and processed by SEPA's team of hydrometrists into the final, qualitycontrolled data product used in this study.

\section{Generation of radar QPEs from NXPol}

Here we describe how the observations from NXPol were collected, calibrated, quality controlled and processed to produce precipitation estimates for comparison to SEPA's rain gauges and the Met Office C-band radar composite rainfall product. These estimates were generated offline, after the data collection period, which allowed consistent processing across the dataset. This processing included radar calibration, beam blockage correction, the removal of spurious echoes, attenuation correction and conversion of radar moments to QPEs. QPEs were generated using a varying number of these processing steps to determine whether dual-polarization radar QPEs improve on single polarization estimates, to investigate the most appropriate dual-polarization estimation technique for this location and to compare with the existing radar coverage in this location. The following section covers the techniques used and how they were combined to create the QPEs used for the analysis.

\section{a. Calibration}

NXPol observations of $Z_{\mathrm{DR}}$ were calibrated through analysis of vertically pointing, i.e., "birdbath," scans. Each vertical scan was averaged over a full rotation in azimuth to generate vertical profiles of each radar moment which were then used to define the part of the observed profile containing an estimate of the $Z_{\mathrm{DR}}$ bias of the system. Based on an assessment of all the observed vertical scans during RAiNS, a single bias correction of $2.0 \mathrm{~dB}$ was applied to the entire dataset. Daily variations in this bias were observed on the order of $\pm 0.2 \mathrm{~dB}$.

After $Z_{\mathrm{DR}}$ had been corrected for bias, horizontal reflectivity $Z_{H}$ was calibrated through application of the selfconsistency technique presented by Gourley et al. (2009). The technique identifies individual rays of rainfall suitable for selfconsistent calibration and compares the observed differential phase shift along the ray (between $4^{\circ}$ and $6^{\circ}$ ) to the simulated phase shift calculated using $Z_{H}$ and $Z_{\mathrm{DR}}$. The difference between the observed and simulated phase shifts are then 
attributed to a miscalibration in $Z_{H}$, as $Z_{\mathrm{DR}}$ is independently calibrated, and a correction may be determined. For the period examined in the RAiNS data the miscalibration in $Z_{H}$ was found to be $1.8 \pm 1.0 \mathrm{~dB}$ and a correction of $1.8 \mathrm{~dB}$ was applied to the whole period.

\section{b. Clutter mitigation}

Ground clutter contamination is a frequent problem for weather radars occurring when radiation is returned from Earth's surface, vegetation, and man-made structures [see Holleman et al. (2006), Fabry (2015), and Ryzhkov and Zrnić (2019) for more details]. Mitigation approaches focus on removing these signals either within the signal processor (e.g., Torres and Zrnić 1999) or from the radar moments after signal processing (e.g., RicoRamirez and Cluckie 2008; Dufton and Collier 2015). Here these approaches are blended to mitigate the loss of weather signals (typically along the zero velocity isodop) that can occur during velocity-based signal processing while maintaining the removal of nonmeteorological echoes (Dufton 2016; Dufton and Collier 2015). The approach utilized here implements a new datamerging scheme for this campaign to combine unfiltered radar moments with IIR filtered moments in regions of persistent clutter. Regions of persistent clutter were defined using a static clutter map using data from six nonconsecutive clear air days spanning the observation period (1735 volume scans), with clutter defined for those voxels where at least $75 \%$ (1302) of the scans contained reflectivity in excess of $10 \mathrm{dBZ}$. This technique was used to blend raw and IIR filtered fields of horizontal reflectivity, differential reflectivity, copolar correlation, and phase shift with a simple binary mask. These combined fields are then used for subsequent processing.

\section{c. Beam blockage correction}

Partial beam blockage occurs when a fraction of the radar beam is obscured, typically by the land surface but also vegetation, buildings, and other structures [in general please see Fabry (2015) and Ryzhkov and Zrnić (2019)]. To correct for this a method of calculating the fraction of beam blocked at each azimuth is required and this is most often done using a digital terrain model in combination with standard beam propagation geometry (e.g., Bech et al. 2003). In this study two methods of correcting for partial beam blockage were applied. First, the technique of Bech et al. (2003) is implemented using open-source code available in wradlib (Heistermann et al. 2013) with a 5-m digital terrain model (DTM) as input. The second method utilizes the dual-polarization radar moments recorded by NXPol to implement the specific attenuation bias calculation method developed by Diederich et al. (2015a). The methodology relies on the calculation of specific attenuation within rainfall, achieved here by implementing the well-known ZPHI method (Testud et al. 2000), which can then be used to generate a synthetic horizontal reflectivity [Eq. (1)]. This method is immune to beam blockage and radar miscalibration as a result of dual-polarization phase information being used as the constraint for calculation of specific attenuation, provided the beam is not $100 \%$ blocked:

$$
Z_{\text {syn }}=a\left(A_{H}\right)^{b} \text {. }
$$

Synthetic reflectivity is then compared to observed reflectivity corrected for attenuation to quantify beam blockage. Diederich et al. (2015a) present two methods for calculating the bias, gate by gate or segment summation, and here the segment summation method is implemented to calculate partial beam blockage using Eq. (2) where the summations are over both time and range along the radar radials:

$$
B_{A}=10 \times \log _{10} \frac{\sum 10^{0.1\left(Z_{\mathrm{syn}}\right)}}{\sum 10^{0.1\left(Z+I A_{H}\right)}} .
$$

In total 1084 volume scans were used to derive the bias estimates, spanning the observation domain to account for variability in the observed drop size distributions. Figure 2 presents the differences between the two methodologies. Clearly using radar specific calculations produces a higher estimate of beam blockage for this location. This is presumed to be a result of significant tree cover in the area, in addition to some man-made structures (masts and turbines) close to the radar, which are not accounted for in the DTM.

\section{d. Filtering of spurious echoes}

Quality control of the radar data included removal of second trip and nonmeteorological echoes. Second trip echoes are removed when normalized coherent power (NCP) is below a variable threshold (between 0.2 and 0.4 ) determined by the ray to ray variation of differential phase shift. Ray to ray variation in second trip echoes results from the staggered PRFs employed during operation, which alters the unambiguous range of the radar causing second trip echoes to shift along the ray. The PRF shift is leveraged here to reduce the incorrect identification of second trip echoes which may occur when using a fixed NCP threshold (Dufton 2016). Nonmeteorological echoes are filtered using a fuzzy-logic classification scheme, which identifies and removes ground clutter, insects and noise using a combination of direct radar moments and texture fields (Dufton and Collier 2015).

\section{e. Radar-based QPEs from NXPol}

Ten methods were used to obtain QPEs from the processed NXPol dataset. These algorithms varied both in the relations between radar-observable and rain rate utilized as well as the level of processing applied to the data before their application. The distinct rainfall relationships utilized were the MP relationship between reflectivity and rain rate (as used by the Met Office; Harrison et al. 2000; Marshall and Palmer 1948), which was applied in all cases of $Z$ to $R$ conversion [Eq. (3)], an algorithm relating specific attenuation to rain rate [Eq. (4)] (Diederich et al. 2015b), and a relation between specific differential phase and rain rate [Eq. (6)] (Ryzhkov et al. 2014). These three processes are shown in Table 1, which briefly covers their advantages and limitations. More information can then be found in the references detailed therein. In total 10 different QPEs were generated and are summarized here, with naming conventions used later in the paper noted within the parentheses of each relation: 

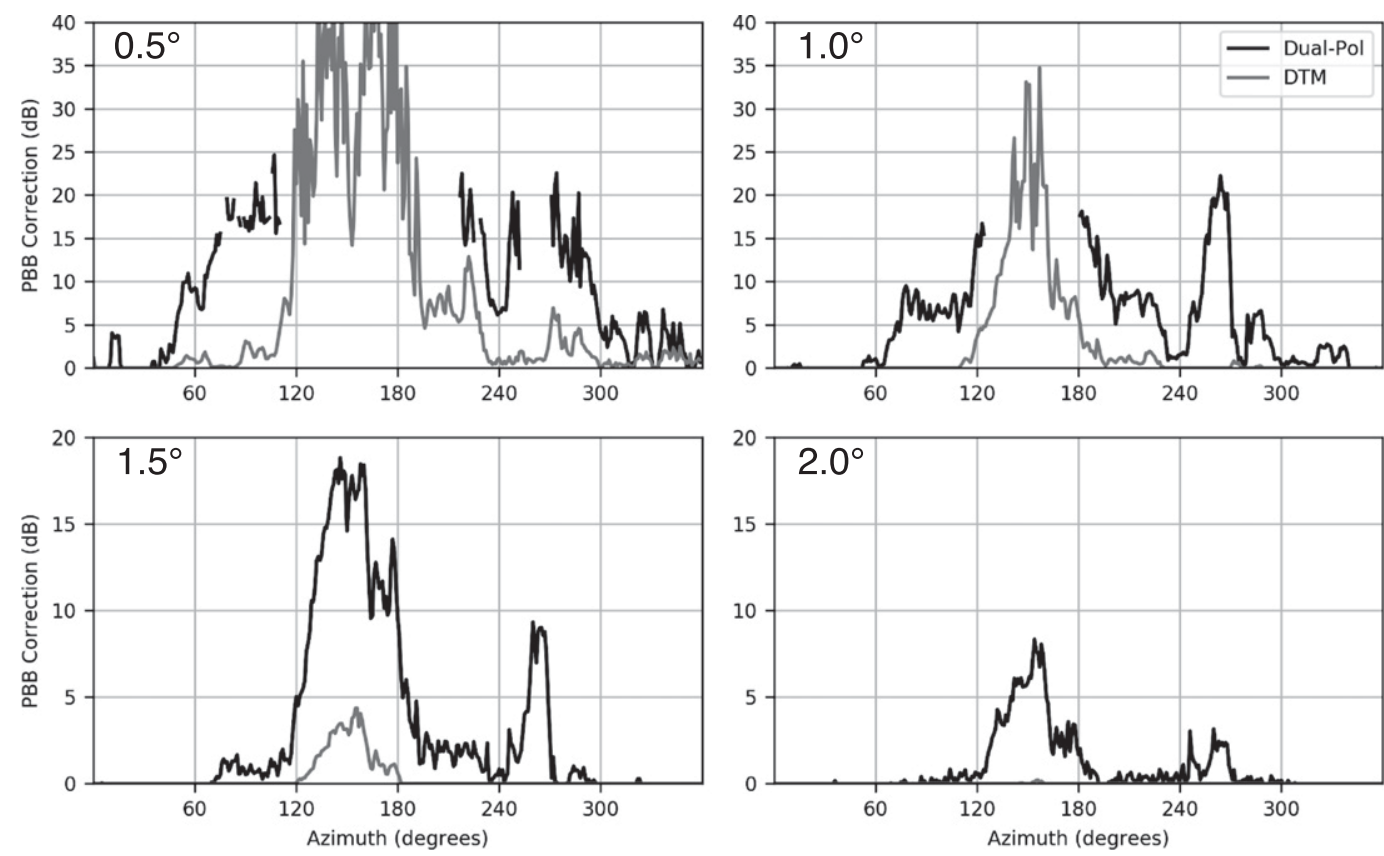

FIG. 2. Partial beam blockage correction at the end of each radial for the lowest four elevation angles in the volume scan $\left(0.5^{\circ}, 1.0^{\circ}, 1.5^{\circ}\right.$, and $\left.2.0^{\circ}\right)$. The solid gray line is computed using a digital terrain model (DTM) and standard beam propagation techniques while the solid black line is computed using dual-polarization consistency methods.

1) $R(Z)$ : A baseline reflectivity-based QPE derived purely from unfiltered horizontal reflectivity data with no postprocessing beyond calibration:

$$
R=\left(\frac{Z}{200}\right)^{1 / 1.6}
$$

2) $R(Z+\mathrm{DTM}):$ A reflectivity based $\mathrm{QPE}$ where simple clutter mitigation (section $3 b$ ) is applied, and the reflectivity is corrected for beam blockage using the DTM approach (section 3c).

3) $R(Z+\mathrm{DTM}+\mathrm{QC})$ : As for $R(Z+\mathrm{DTM})$ but with the removal of spurious echoes (section $3 \mathrm{~d}$ )

4) $R(Z+\mathrm{DTM}+\mathrm{QC}+\mathrm{Att}):$ As for $R(Z+\mathrm{DTM}+\mathrm{QC})$ but using beam blockage corrected and filtered reflectivity that is also corrected for attenuation using the ZPHI method (Testud et al. 2000) prior to precipitation estimation.

5) $R(\mathrm{ZC})$ : A beam blockage corrected and filtered reflectivity that is again corrected for attenuation using the ZPHI method prior to precipitation estimation. However, in this case beam blockage is instead corrected using the specific attenuation derived beam blockage clutter map.

6) $R\left(A_{H}\right)$ : Conversion of specific attenuation to rain rate using a fixed $R(A)$ relationship [Eq. (4)] based on an atmospheric temperature of $10^{\circ} \mathrm{C}$ (Diederich et al. 2015b). Where specific attenuation is not estimated due to the restrictions of the $Z \mathrm{PHI}$ method (above the melting level, for example), $R(\mathrm{ZC})$ is used as a fall back for data continuity.

$$
R=45.5 A_{H}^{0.83}
$$

7) $R\left(A_{H, \mathrm{thr}}\right): R(A)$ now limited to those radials where the total differential phase shift is greater than $5^{\circ}$, where the estimation of $A_{H}$ is more accurate. As for $R\left(A_{H}\right), R(\mathrm{ZC})$ is used as a fallback in all other cases.

8) $R\left[Z\left(A_{H}\right)\right]$ : Instead of using specific attenuation to directly estimate rainfall $A_{H}$ is instead converted to reflectivity, as is required for calculating beam blockage (Diederich et al. 2015a), and then this reflectivity is converted to a rain rate using the MP relationship. This approach removes bias due to miscalibration and beam blockage directly, accounting for any dynamic changes that could be affecting the radar. These estimates are again restricted to those radials where the total differential phase shift is greater than $5^{\circ}$ with $R(\mathrm{ZC})$ being used to infill other regions.

$$
Z=\left(\frac{A_{H}}{0.000115}\right)^{1 / 0.78}
$$

9) $R\left(K_{\mathrm{dp}}-Z\right)$ : This method utilizes specific differential phase $K_{\mathrm{dp}}$ to estimate precipitation intensity, using the relationship from Ryzhkov et al. (2014). Given the well-known issues of estimating small values of $K_{\mathrm{dp}}$ (Vulpiani et al. 2012; Hu et al. 2015) these estimates are blended with those from $\mathrm{ZC}$ at all intensities lower than $20 \mathrm{~mm} \mathrm{~h}^{-1}$ using a weighted average [Eq. (4)].

$$
R=w\left(16.9 K_{\mathrm{dp}}\right)^{0.801}+(1-w)\left(\frac{Z}{200}\right)^{1 / 1.6}
$$

where $w$ varies between 0 and 1 as $R\left(K_{\mathrm{dp}}\right)$ varies from 10 to $20 \mathrm{~mm} \mathrm{~h}^{-1}$.

10) $R$ (dual-pol): As for $R\left[Z\left(A_{H}\right)\right]$ but $R\left(K_{\mathrm{dp}}-Z\right)$ is used to infill regions where $A_{H}$ could not be calculated accurately instead of infilling with $R(\mathrm{ZC})$.

Of the 10 estimates, the first five utilize method 1 from Table 1 , methods 6 and 7 utilize method 3 and method 1 in combination, 
TABLE 1. Rainfall algorithms used in this study and their advantages and limitations.

\begin{tabular}{|c|c|c|c|c|c|}
\hline Method & Algorithm & Advantages & Limitations & Mitigation & Reference \\
\hline$R\left(Z_{H}\right)$ & $Z_{H}=200 R^{1.6}$ & $\begin{array}{l}\text { Only requires reflectivity } \\
\text { measurements (i.e., } \\
\text { not a dual- } \\
\text { polarization radar). } \\
\text { Locally accepted co- } \\
\text { efficients available. }\end{array}$ & $\begin{array}{l}\text { Accuracy is highly } \\
\text { sensitive to variations } \\
\text { in the DSD. } \\
\text { Reflectivity is prone to } \\
\text { many sources of error. }\end{array}$ & $\begin{array}{l}\text { Processing of reflectivity } \\
\text { to remove errors. } \\
\text { Local } Z-R \\
\text { relation used. }\end{array}$ & $\begin{array}{l}\text { Bringi and } \\
\text { Chandraskar } \\
\text { (2001); Harrison } \\
\text { et al. (2012) }\end{array}$ \\
\hline$R\left(K_{\mathrm{dp}}\right)$ & $R=16.9 K_{\mathrm{DP}}^{0.801}$ & $\begin{array}{l}\text { Relation is less sensitive } \\
\text { to variations in the } \\
\text { DSD and radar } \\
\text { measurement errors. }\end{array}$ & $\begin{array}{l}\text { Uncertain estimation of } \\
K_{\mathrm{dp}} \text {. Lower resolution. }\end{array}$ & $\begin{array}{l}\text { Blending with } R\left(Z_{H}\right) \\
\quad \text { when rainfall is light. }\end{array}$ & $\begin{array}{l}\text { Brandes et al. } \\
\text { (2001); } \\
\text { Wang and } \\
\text { Chandrasekar } \\
\text { (2009) }\end{array}$ \\
\hline$R\left(A_{H}\right)$ & $R=45.5 A_{H}^{0.83}$ & $\begin{array}{l}\text { Less sensitive to DSD } \\
\text { variation and radar } \\
\text { measurement errors } \\
\text { (PBB and } \\
\text { miscalibration). } \\
\text { Estimation is possible } \\
\text { at native radar } \\
\text { resolution. }\end{array}$ & $\begin{array}{l}\text { Accurate estimation of } \\
A_{H} \text { depends on the } \\
\text { weather situation. Not } \\
\text { possible to apply to } \\
\text { solid phase } \\
\text { hydrometeors. }\end{array}$ & $\begin{array}{l}\text { Threshold estimation of } \\
A_{H} \text {. Only use below } \\
\text { the melting layer. }\end{array}$ & $\begin{array}{l}\text { Diederich et al. } \\
\text { (2015b); } \\
\text { Ryzhkov } \\
\text { et al. (2014) }\end{array}$ \\
\hline$R$ (dual-pol) & $\begin{array}{l}\text { Use a hierarchy of } \\
\text { availability in } \\
\text { the order: } R\left(A_{H}\right), \\
R\left(K_{\mathrm{dp}}\right), R\left(Z_{H}\right)\end{array}$ & $\begin{array}{l}\text { Combining methods } \\
\text { offsets limitations in } \\
\text { each method and data } \\
\text { availability. }\end{array}$ & $\begin{array}{l}\text { Light rain still requires } \\
R\left(Z_{H}\right) \text {. Combination } \\
\text { of errors depending on } \\
\text { which algorithm is } \\
\text { used-potentially } \\
\text { precludes use of } \\
\text { conventional bias } \\
\text { corrections. }\end{array}$ & $\begin{array}{l}\text { No bias correction } \\
\text { applied in this study, } \\
\text { consider implications } \\
\text { in future work. }\end{array}$ & \\
\hline
\end{tabular}

and estimate 9 uses method 2 and method 1 in combination. Estimate 8 uses method 1 but the limitations are offset by the use of a synthetic reflectivity where available which is derived from specific attenuation. Finally, method 10 combines the three methods in Table 1 in a hierarchical structure. Each of the 10 estimates was generated to investigate the benefits of different components of a dual-polarization processing workflow. Note that all of these relations are based upon the correlation of observed parameters from previous studies which examine observations that may be very different from those shown here. Thus, we apply these relations with the assumption such correlations are valid here. Estimates 1-5 are used to investigate the benefits of dualpolarization over single polarization (section 4a) whereas 6-10 are used to examine the different approaches that can be taken when using a dual-polarization weather radar in the Inverness or similar mountainous regions with typically low melting layers. Methods utilizing differential reflectivity have been omitted from these approaches as they are often susceptible to large uncertainty in the presence of attenuation, particularly at X-band, which can have significant impacts on the reliability of the resulting QPEs. Method 10 represents an approach for combining the algorithms to provide a widely applicable QPE for this region, as discussed in section $4 \mathrm{~b}$.

\section{f. $2 D Q P E$ product for comparison to rain gauges and Nimrod QPES}

To compare the derived QPEs from the NXPol to the observations from the rain gauges and Met Office estimates we chose to use data from the lowest usable elevation (LUE) rather than interpolating our observations to a constant altitude above the surface and/or gridding the NXPol observations or derived rain products. The elevation of the lowest radar beam that can be considered as usable (i.e., does not include significant blockages or intrusion by clutter) considering data quality constraints is shown in Fig. 3a. This is determined using two factors: first, the percentage clutter fraction and second, the minimum detectable signal considering beam blockage as derived using specific attenuation. If either the clutter fraction exceeds $75 \%$ or the minimum detectable signal exceeds $10 \mathrm{~dB}$ at a given elevation then the gate is flagged as unusable and the next elevation up is checked instead, up to a limit of $4^{\circ}$. Figure $3 b$ depicts the corresponding height of that beam in relation to mean sea level assuming standard atmospheric beam propagation. This was done to remove a layer of opacity and uncertainty created when such interpolations and gridding is applied to data. By utilizing this method, we are able to easily identify data quality issues related to ground clutter, range and the melting band in the NXPol observations and data products.

\section{g. Radar-derived TBR time series at rain gauge locations}

After creating the 2D LUE product of each of the rainfall estimates, a time series of data at the locations of the rain gauges was derived using the extraction and zonal statistics tools in the wradlib Python package. For details of these methods, please see Heistermann et al. (2013). Note that the data were not gridded 

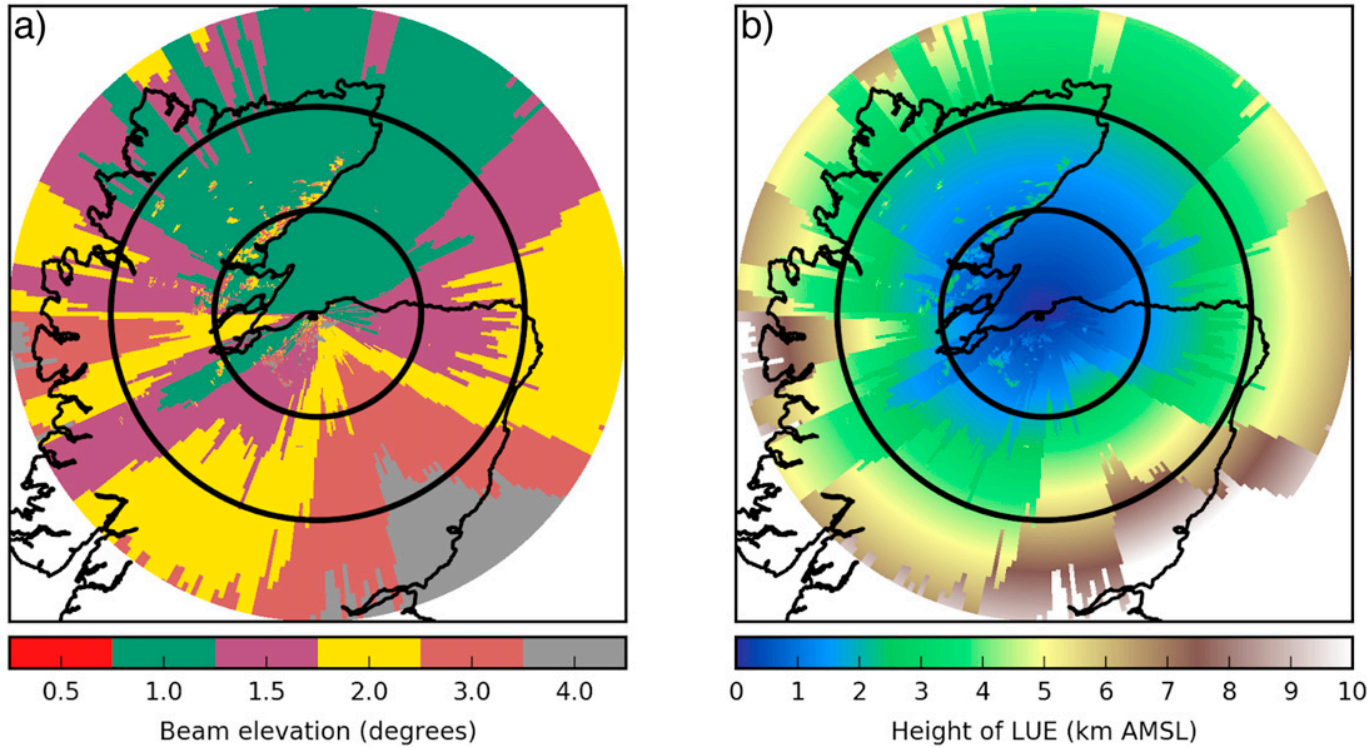

FIG. 3. (a) A map depicting the LUE for RAiNS where the color represents the elevation angle of the beam used to derive rainfall over that location and (b) the corresponding height of the beam in (a) in relation to mean sea level assuming standard atmospheric beam propagation. Each panel is a $300-\mathrm{km}$ square centered on the radar location with range rings located at 50 and $100 \mathrm{~km}$ from the radar. The coastline of Scotland is shown in black on each image to provide geographic context.

between these steps and the data were extracted from the original polar grid of the radar at the LUE above each rain gauge. For the rain gauge comparisons, we averaged the nearest five radar data voxels to each of the gauges.

\section{Results}

Here we make a comparison of the point rainfall estimates for the Inverness and Moray Firth region generated from SEPA's operational rain gauge network, the NXPol's LUE QPE products and the Met Office's operational radar network to address the questions of the RAiNS campaign. First, we compare dualpolarization data processing and QPE methods to more traditional data processing and QPE methods (section 4a). We then examine several variations in the dual-polarization methods to further understand what advantages these techniques afford QPEs (section 4b). Finally, we compare the results of the NXPol's dual-pol QPE method to the Met Office's Nimrod rainfall product to understand the possible benefits of high temporal and spatial resolution radar precipitation estimates in northern Scotland (section 4c). Note that in all analyses where the rain gauges observed less than $1 \mathrm{~mm} \mathrm{~h}^{-1}$, the radar and rain gauge data at that time step were removed from the statistical analyses.

\section{a. The challenges of topography and attenuation: Comparison of single- and dual-polarization QPE methods}

Complex topography poses several challenges for weather radar observations of surface precipitation. Low elevation scans are often subject to blockage and frequent ground clutter returns in these environments, while higher elevations suffer from overshooting and vertical gradients in precipitation intensity. The differing rainfall accumulations derived from the
NXPol observations shown in Fig. 4 highlight these difficulties. Each column in Fig. 4 depicts a different method of QPE, and each row depicts a different elevation angle approach (either fixed at $1.0^{\circ}$ and $3.0^{\circ}$ or LUE). The $1.0^{\circ}$ QPE scans (Fig. 4, top row) clearly shows the regions subject to almost complete beam blockage. The region to the southeast of the NXPol shows evidence of significant blockage due to changes in topography close to the radar (300-m elevation gain within $15 \mathrm{~km}$ ) while the smaller sector to the west is due to blockage caused by a tree covered headland located close to the radar (within $5 \mathrm{~km}$ ). The $3.0^{\circ}$ scan avoids these blockages but utilizing scans at this elevation severely limits the usable range $(\sim 50 \mathrm{~km})$ of the radar for QPE. Comparison of the accumulations at the two fixed elevations to the accumulations combined into the LUE product for each method (i.e., the columns of Fig. 4) shows that the LUE product provides a spatially improved estimate of precipitation compared to any single elevation. The difference is especially evident in the region in the southeast quadrant of data where intermediate elevations $\left(1.5^{\circ}, 2^{\circ}\right.$, and $\left.2.5^{\circ}\right)$ infill the data where the $1.0^{\circ}$ elevation data are blocked by mountainous terrain, and the $3.0^{\circ}$ elevation is too high to provide representative information at far ranges. As such, the LUE makes use of all available elevations to provide the best data coverage across the NXPol's observed domain.

For all QPE methods the accumulations in Fig. 4 decrease with range even over the relatively unblocked section of observations over the Moray Firth. This is due to overshooting, decreased sensitivity and attenuation. Diederich et al. (2015b) and Pellarin et al. (2002) and others similarly observed this, particularly when using X-band radar. In sectors beyond regions with large changes in surface elevation close to the NXPol (such as the region to the southeast) where QPE 


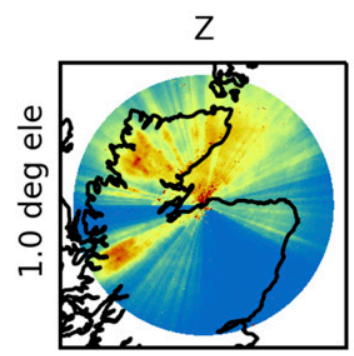

$\mathrm{Z}+\mathrm{DTM}+\mathrm{QC}+\mathrm{Att}$
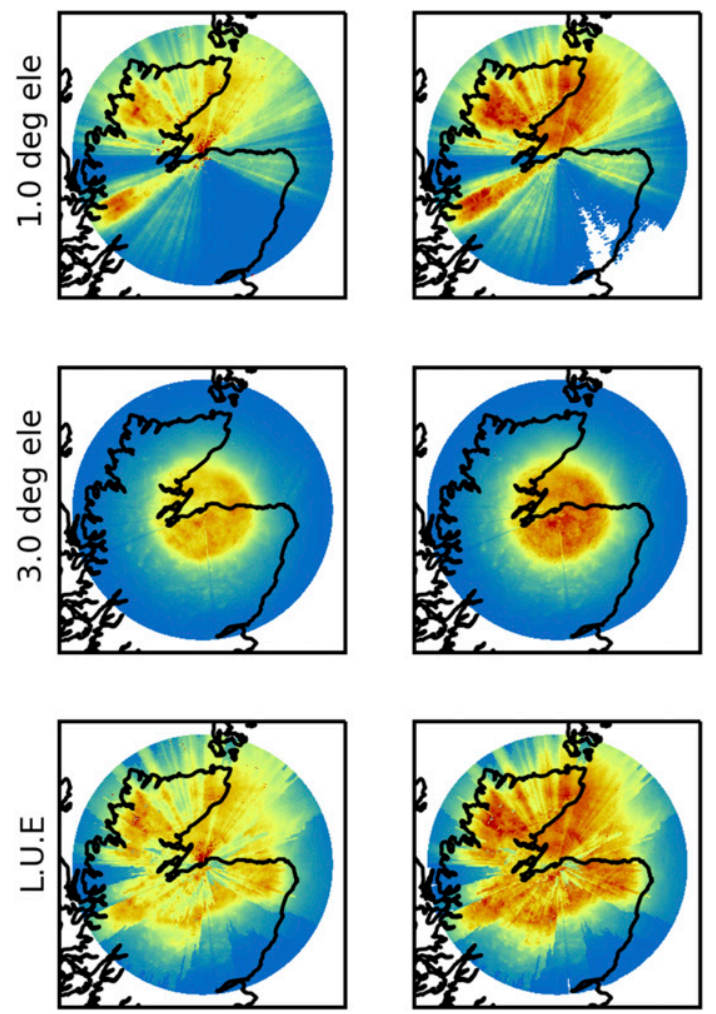


FIG. 4. Total rainfall accumulations during June-August 2016 as observed by NXPol. Each column depicts a different method of radar QPE and each row depicts a different elevation angle approach (either fixed at $1.0^{\circ}$ and $3.0^{\circ}$, or LUE). Each panel is a $300-\mathrm{km}$ square centered on the radar location. The coastline of Scotland is shown on each panel to provide geographic context.

estimates are derived from higher elevation scans there is still significant variation due to the challenges associated with an overshooting beam and changes in the vertical profile of reflectivity (i.e., the VPR effect). These are most pronounced where the LUE data come from beams with an altitude above $5 \mathrm{~km}$ (Fig. 3).

Despite these common artifacts, for each row, the addition of extra processing improves the QPEs. Using a DTM for beam blockage correction and additional clutter removal (second column from the left of Fig. 4) shows minimal advantage as there are only localized changes in the consistency and total of the accumulation maps, with many of the blocked sectors still being clearly visible, such as to the south west and east. The addition of attenuation corrections $(Z+\mathrm{DTM}+\mathrm{QC}+\mathrm{Att})$ generates increased rainfall totals over the northwestern Highlands and in the unblocked sector to the south west but rainfall totals in blocked sectors remain low. Changing the beam blockage correction to a dual-polarization derived estimate shows a marked increase in the total rainfall observed over the entire domain with blockage to the east being far less visible and to the south west showing increased totals at $1^{\circ}$ elevation (the far right panel of the top row of Fig. 4). The $3^{\circ}$ elevation also indicates the benefit of this approach to beam blockage correction with the small blocked sectors to the south and west being corrected for using this technique, suggesting that the elevated levels of blockage derived by the attenuation method (shown in Fig. 2) are more representative of actual blockage than the DTM approach.

The issues of attenuation in $\mathrm{X}$-band radars, as shown by the differences between $Z+\mathrm{DTM}+\mathrm{QC}$ and $Z+\mathrm{DTM}+\mathrm{QC}+$ Att in Fig. 4, are well known. Less well characterized are the dual-polarimetric methods for beam blockage in X-band radar discussed by Diederich et al. (2015a,b). Methods similar to those of Diederich et al. (2015a,b) are adopted here and Fig. 4 suggests that the beam blockage corrections based on dualpolarimetric observations have a clear advantage compared to traditional DTM blockage correction methods, particularly in mountainous, and heavily forested, locations such as northern Scotland.

\section{b. Examination of dual-polarization QPE methods}

Figure 5 compares the bias, error, and correlation in the hourly accumulation between all dual-polarization NXPol QPE methods as compared to the observations from the 64 SEPA rain gauges across the Inverness region. Note that the radar-based and rain gauge based QPEs will never have identical statistical distributions due to the physical differences and errors associated with each type of measurement. Even so, here we use the rain gauge observations as a baseline for the comparison of all the radar-based QPE methods. 



FIG. 5. Comparison of the hourly accumulation (top) bias, (middle) error, and (bottom) correlation between all the dualpolarization NXPol QPE methods as compared to the observations from the 64 SEPA rain gauges across the Inverness region. The box-and-whisker plots represent the $9 \%, 25 \%, 50 \%, 75 \%$, and $91 \%$ percentiles with dots representing outliers.

All the radar-based QPE methods shown in Fig. 5 underestimate the hourly rainfall rates as compared to the rain gauges and have similar levels of bias $\left(\sim-1 \mathrm{~mm} \mathrm{~h}^{-1}\right)$, error $\left(\sim 1 \mathrm{~mm} \mathrm{~h}^{-1}\right)$ and correlation $(\sim 0.75)$. The use of specific attenuation to derive rain rate $\left(A_{H}\right.$ and $\left.A_{H, \text { thr }}\right)$ provides a small improvement compared to $\mathrm{ZC}$ as seen in the slight increase in correlation. However, this is at the expense of an increase in the negative bias (note that the $A_{H}$ and dual-pol products have the smallest range of bias across all gauges in comparison to the other QPE methods). There is also no impact on the worst performing gauges in terms of correlation (outliers) as these gauges are all in regions where estimates are derived from above the melting layer (hence $A_{H}$ is not calculated and has no effect). The $Z\left(A_{H}\right)$ method has a slightly worse bias compared to ZC but displays a small improvement in error and correlation.

The slightly improved correlation seen in the $A_{H}, A_{H, \mathrm{thr}}$, $Z\left(A_{H}\right)$ methods is due to the fact that these methods directly account for biases due to miscalibration and beam blockage so that any dynamic changes that could be affecting the radar observations are reduced. The small difference in bias between the direct conversion of specific attenuation to rain rate and the indirect method $\left[Z\left(A_{H}\right)\right]$, which utilizes the MP conversion, suggests that even though the specific attenuation based methods provide better consistency, these methods are limited in their ability to provide accurate QPE over a wide range of conditions. Further investigation of specific attenuation may result in improved QPEs, but this was beyond the scope of this study.

The $K_{\mathrm{dp}}-Z$ method has the smallest median bias of all the investigated precipitation algorithms and a much narrower range of bias across the gauges. The $K_{\mathrm{dp}}-Z$ method also leads to an improvement in error for the worse performing $50 \%$ of the gauges studied. The improvements come from regions where $\mathrm{ZC}$ is infilling in each of the specific attenuation products as seen by a common tail in the error and bias plots [ZC, $A_{H}$, $A_{H \text {,thr }}$, and $Z\left(A_{H}\right)$ ] indicating the same data are being used at these locations in each case, which improves when switching to $K_{\mathrm{dp}}-Z$. This is due to the ability of $K_{\mathrm{dp}}-Z$ to provide more accurate estimates of moderate and intense precipitation $\left(>10 \mathrm{~mm} \mathrm{~h}^{-1}\right)$, especially for X-band radars that generate elevated $K_{\mathrm{dp}}$ at lower precipitation rates (relative to $\mathrm{C}$ and $\mathrm{S}$-band) making estimation more effective at lower intensities. The dual-pol method, which is a combination of $Z\left(A_{H}\right)$ and $K_{\mathrm{dp}} Z$, shows similar improvements as compared to $\mathrm{ZC}$, though it has a slightly worse bias and only a small improvement in error compared to $K_{\mathrm{dp}}-Z$. This result suggests that a solution that optimally combines several methods where they are most effective is needed and is consistent with earlier studies [in particular, the results of Diederich et al. (2015b)].

Figure 6 is comparable to the bottom row of Fig. 4 (i.e., the LUE product) but for all six dual-polarization QPE methods being examined. Figure 6 depicts the results shown in Fig. 5 but also visualizes them across the whole spatial domain in order to highlight the topographic influence of the region. There are several regions, particularly to the southeast and west of NXPol where all the products underestimate accumulations as a result of beam blockage and overshooting. Comparison to Fig. 3 indicates these are the regions where the LUE product is being sampled at a height in excess of $5 \mathrm{~km}$. Overall, the $K_{\mathrm{dp}}-Z$ and dual-pol methods result in larger total accumulations over most of the observed domain compared to the other methods. Most prominent are the increases $(\sim 50-100 \mathrm{~mm})$ over the regions of higher topography south and northwest of the radar.

The overall performance of the methods is more clearly shown in Table 2 and Fig. 7. Table 2 shows the total number of rain gauges where the six different dual-polarization methods 

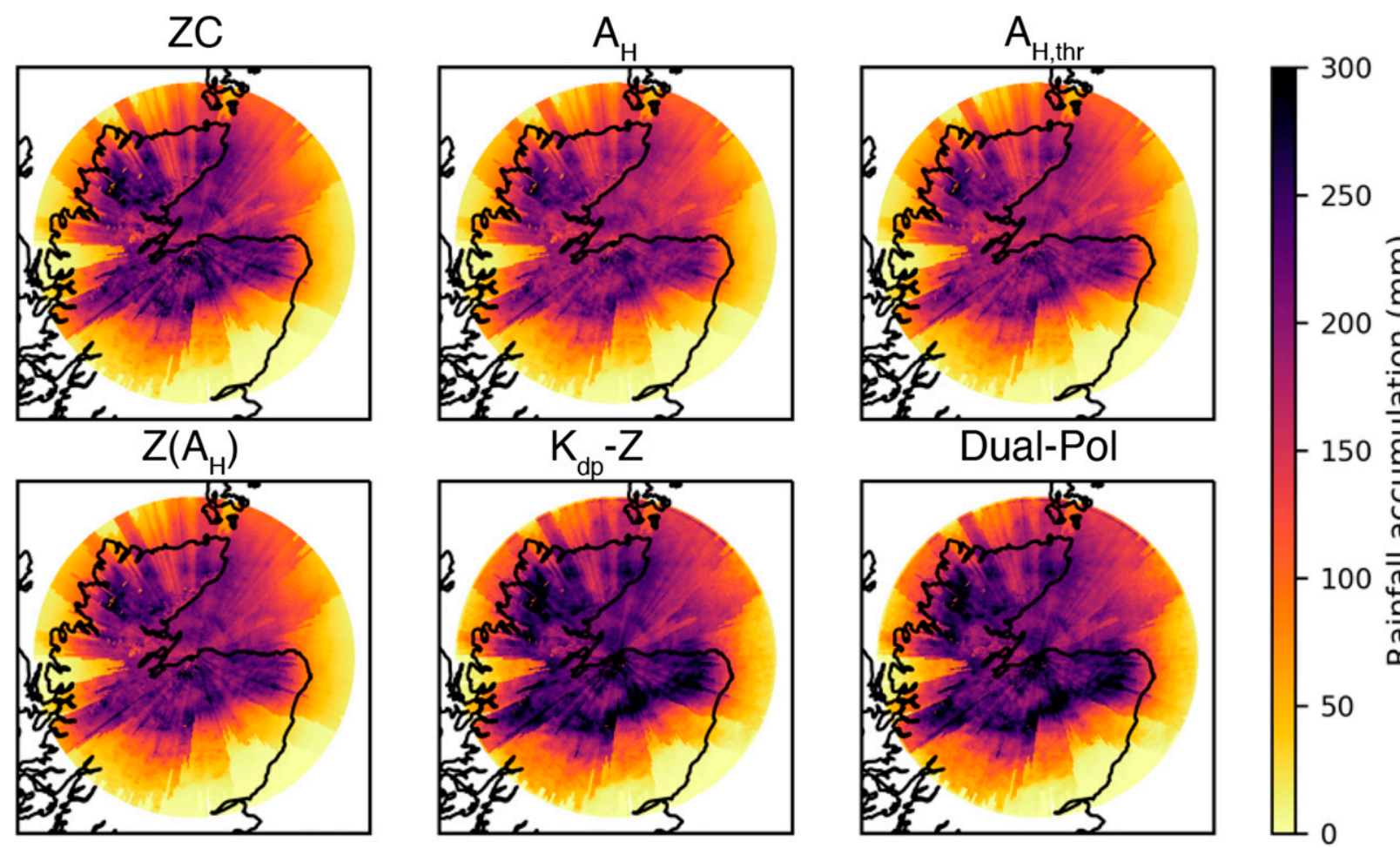

FIG. 6. As in the bottom row (i.e., data at the LUE) of Fig. 4, but for all six dual-polarization QPE methods being examined.

perform best [i.e., rank 1 of these six methods; the total in each column is the total number of rain gauges (i.e., 64)] in terms of bias, error, and correlation. Figure 7 depicts the spatial distribution of the rankings in Table 2. The highlighted station in each of the maps indicates that that method performed best at that location for that metric compared to all the other methods. In Table 2 and Fig. 7, there are a significant number of instances where the dual-pol and $K_{\mathrm{dp}}-Z$ method jointly rank first. This is a consequence of the dual-pol algorithm's definition that uses the $K_{\mathrm{dp}}-Z$ relation to infill regions where $A_{H}$ cannot be accurately determined, particularly above the melting layer. Thus, instances where the dual-pol method and $K_{\mathrm{dp}}-Z$ relation jointly rank first indicate $A_{H}$ is never incorporated into the estimates at these locations (most likely due to a LUE in excess of the melting layer at all times) and should be combined with the scores of $K_{\mathrm{dp}}-Z$ relationship alone when considering the overall utility of the individual relationships. We have not combined these in Table 2 or Fig. 7 as the separation illustrates the spatial behavior of the dual-pol and $K_{\mathrm{dp}}-Z$ relationships.

Table 2 shows that the $K_{\mathrm{dp}}-Z$ relationship performs the best overall in terms of bias, error and correlation. Combined, $K_{\mathrm{dp}}-Z$ has the best bias at 53 of the 64 gauges ( $\sim 83 \%)$, the best error at 33 of the 64 gauges $(\sim 52 \%)$, and best correlation at 22 of the 64 gauges $(\sim 34 \%)$. The reduced number of sites having the best (i.e., lowest) error score compared to the number of sites with the best bias score suggests accumulation based on the rainfall rates of the $K_{\mathrm{dp}}-Z$ relation balances variations between over and underestimation over time.
Note that $K_{\mathrm{dp}}-Z$ and dual-pol only jointly rank first beyond $50 \mathrm{~km}$ (last row of Fig. 7) while closer to NXPol, the results are mixed as $K_{\mathrm{dp}}-Z$ is best in terms of bias (35 of 64) and correlation (13 of 64) while the dual-pol methods is best in terms of error (22 of 64). This spatial dependence suggests that $K_{\mathrm{dp}}-Z$ is outperforming $\mathrm{ZC}$ at ranges where the precipitation is the hardest to detect. This spatial dependence also suggests that the $K_{\mathrm{dp}}-Z$ relation chosen for this study is producing representative rainfall rates from observations above the melting band (i.e., in regions of ice and mixed phase hydrometeors) despite the parameters of this relationship being based on the expected attenuation of liquid hydrometeors. This result indicates that a targeted $K_{\mathrm{dp}}-Z$ method that differentiates between liquid, mixed phase, and ice could lead to further performance improvements.

The dual-pol method performs second best when looking at the full domain in terms of error with 22 of the $64(\sim 34 \%)$

TABLE 2. Number of rain gauges where the six different dualpolarization methods perform best (i.e., rank 1 of these six methods).

\begin{tabular}{lccc}
\hline \hline & Bias $(\mathrm{mm})$ & Error $(\mathrm{mm})$ & Correlation \\
\hline $\mathrm{ZC}$ & 6 & 0 & 13 \\
$A_{H}$ & 0 & 0 & 7 \\
$A_{H, \text { thr }}$ & 0 & 4 & 6 \\
$Z\left(A_{H}\right)$ & 0 & 5 & 11 \\
$K_{\mathrm{dp}}-Z$ & 35 & 15 & 13 \\
Dual-pol & 5 & 22 & 5 \\
Joint $K_{\mathrm{dp}}-Z$ and dual-pol & 18 & 18 & 9 \\
\hline
\end{tabular}




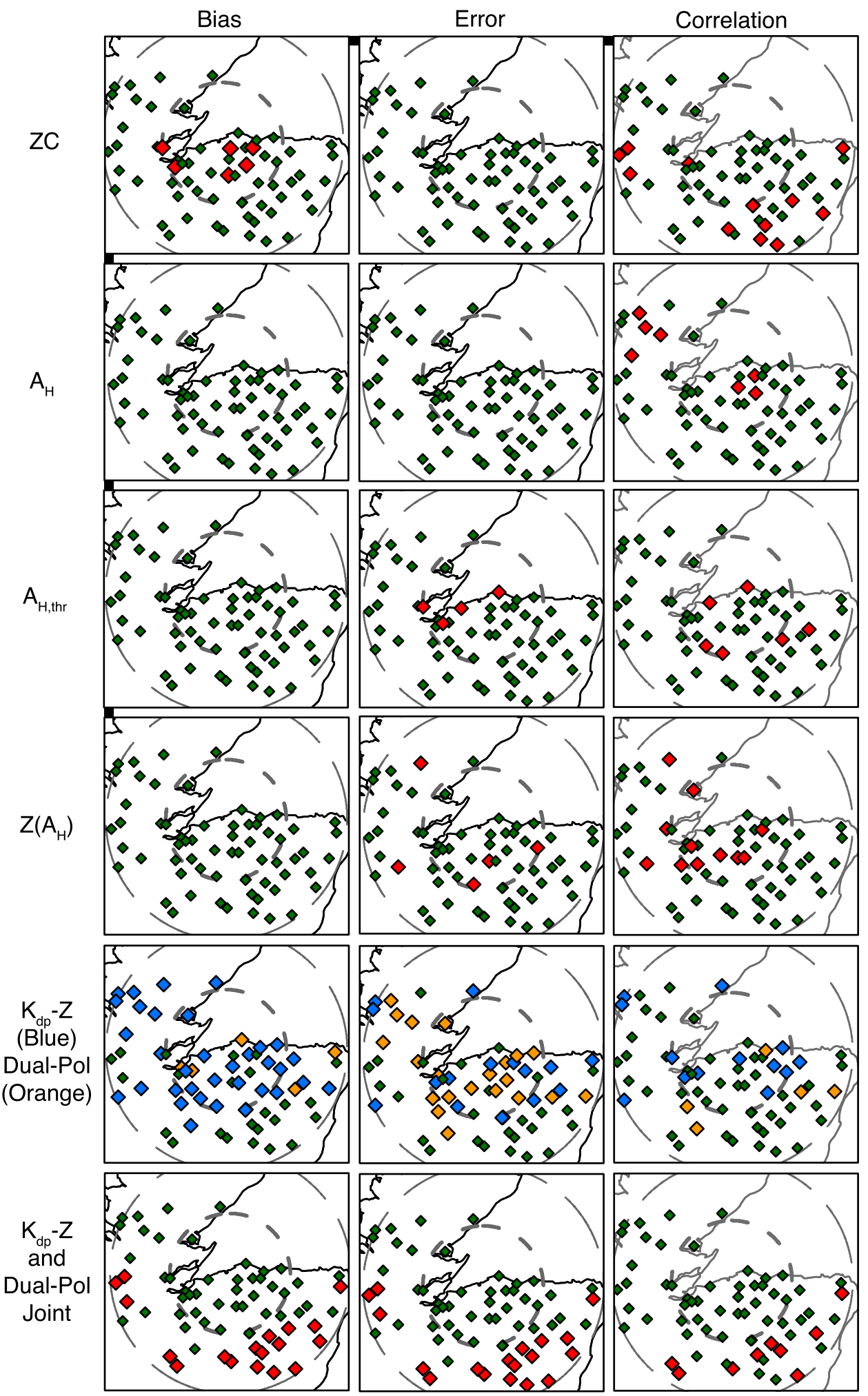

FIG. 7. The spatial distribution of the best performing (i.e., ranked first) dual-polarization QPE method as compared to rain gauge observations. Performance evaluated using (left) bias, (center) error, and (right) correlation compared to rain gauge observations. In all subplots the highlighted stations show where that method performed best according to the metric being examined. The $K_{\mathrm{dp}}-Z$ and dual-pol methods are shown together to help examine the subtleties of combining underlying algorithms within the dual-pol method. The inner and outer dashed rings represent the 50- and 100-km ranges, respectively. 
gauges ranked first. Comparatively, with respect to bias the dual-pol and ZC relationships perform similarly and much worse than $K_{\mathrm{dp}}-Z$ in terms of the number of sites (6 and 5, respectively) ranked first. Figure 5 shows that although the dual-pol method does not have the best median bias overall, the distribution in the bias is the smallest. Together these results suggest that there is a systematic error in the relationship within the dual-pol method that could be corrected with further investigation. As the dual-pol method only performs well in regions where specific attenuation may be estimated below the melting layer, the spatial pattern of performance follows the topography of the region (comparing Figs. 3 and 7). Notably, in addition to sites at close range, the dual-pol method outperforms the other relations at several sites to the southwest of the NXPol along the Great Glen and to the northwest of the NXPol across the Moray Firth.

None of the specific attenuation techniques perform better than the other techniques in terms of bias but they do have some advantages in terms of correlation. Figure 5a suggests that this is due to a systematic underestimation of rainfall by these methods. This behavior could possibly be improved through the use of parameters that were set dynamically rather than using those for a fixed temperature as was done here. Such explorations were beyond the scope of this study.

Although $K_{\mathrm{dp}}-Z$ is shown to have some advantage when it comes to correlation compared to the other relationships, the wider picture for correlation is much more varied as compared to bias and error. This mirrors the results of Fig. 5c, which shows that correlation has the least change across the different relationships. Though this may be self-evident, the performance of the correlation clearly shows that the ultimate limit of any of the radar-rainfall relationships examined here is the ability of the NXPol to detect the precipitation at all.

The joint rankings suggest that overall, specific differential phase-based rain rates provide the best performance advantages in this region for X-band QPE. In particular, combining the results of Fig. 5 with Table 2 and Fig. 7 shows that the $K_{\mathrm{dp}}-Z$ relation provides the most benefit at the sites that are the most difficult to observe (i.e., furthest and most impacted by topography), while the combination of relationships utilized in the dual-pol method is effective (high correlations, smaller errors and a smaller spread in the distribution of the bias) where the NXPol is able to observe precipitation close to the surface.

\section{c. Comparison of the NXPol QPE to the Nimrod $Q P E$ product}

In this section we compare the LUE QPE based on the dualpol method from the NXPol to the UKMO's Nimrod QPE product. In contrast to NXPol, the Nimrod processing includes correction for the vertical profiles of reflectivity (VPR), the application of orographic enhancement and also rain gauge bias adjustment. Such corrections are based on years of data analysis and include additional numerical weather model data that were found to be intractable for inclusion in the NXPol data processing at this time. If a radar like NXPol was deployed operationally in the Inverness region these additional adjustments would bring further improvements to the QPE products.
Figure 8 is similar to Fig. 7 in that it shows the spatial distribution of the highest ranked product with respect to bias, error, and correlation but here we only compare the dual-pol method (green) to Nimrod (red). The Nimrod product performs better than the NXPol's dual-pol method at 51 sites for bias (Fig. 8a), 41 sites for error (Fig. 8b), and 39 sites for correlation (Fig. 8c). The spatial pattern in the performance clearly shows that a radar located near the RAiNS deployment site has an advantage for QPE near the Inverness region that runs toward Loch Ness in the southwest sector of the NXPol observations. Figure 8 also shows the advantage of making observations in this region for the coastal areas around the Moray Firth. Over the Highlands to the west, south and southeast, the proximity of the Met Office radar's shows a clear advantage in the Nimrod product's performance.

These patterns are perhaps unsurprising as NXPol performs better where it can sample at low altitudes, which are conversely regions where the C-band radars suffer more from beam blockage and overshooting effects. This suggests that a low elevation QPE made using dual-polarization techniques outperforms higher elevation observations subject to a more complex processing chain including VPR correction. The implication of this are that the dual-polarization upgrade of the C-band radars will not lead to a significant improvement in QPE across this region as those observations will still be subject to the problems of high-altitude sampling. The most likely benefits are to be derived from improved beam blockage calculations (using specific attenuation) and from the application of $K_{\mathrm{dp}}$-based precipitation estimates, particularly in the ice phase region of clouds, although this is more difficult at C-band as gradients in differential phase shift are lower (particularly in ice).

\section{Summary and conclusions}

The results of this study highlight the challenges of observing precipitation over the complex terrain of northern Scotland. This work demonstrates the potential for improved analysis and forecasting of precipitation in using a gap-filling dualpolarization radar, such as the NXPol, that can provide high spatial and temporal resolution observations in the region of interest. The results also show that the benefits of QPEs derived from dual-polarized radar observations can be realized despite the complex terrain.

Results based on the comparison of these precipitation estimates with observations from SEPA's rain gauge network (64 sites) show that a dual-polarization radar can mitigate some of the effects of complex topography through echo classification, quality control and attenuation-based beam blockage correction. Selective usage of differing elevation angles can also compensate for these uncertainties as shown by the lowest usable elevation technique applied to the data. Due to the orography of northern Scotland, there are still several sites where meaningful precipitation estimates are not possible even with improved processing techniques (as shown by the outliers in correlation of Fig. 5c). These sites are located where the beam height of the lowest usable elevation exceeds $5 \mathrm{~km}$ exacerbating the issues caused by overshooting and vertical gradients of precipitation intensity. 

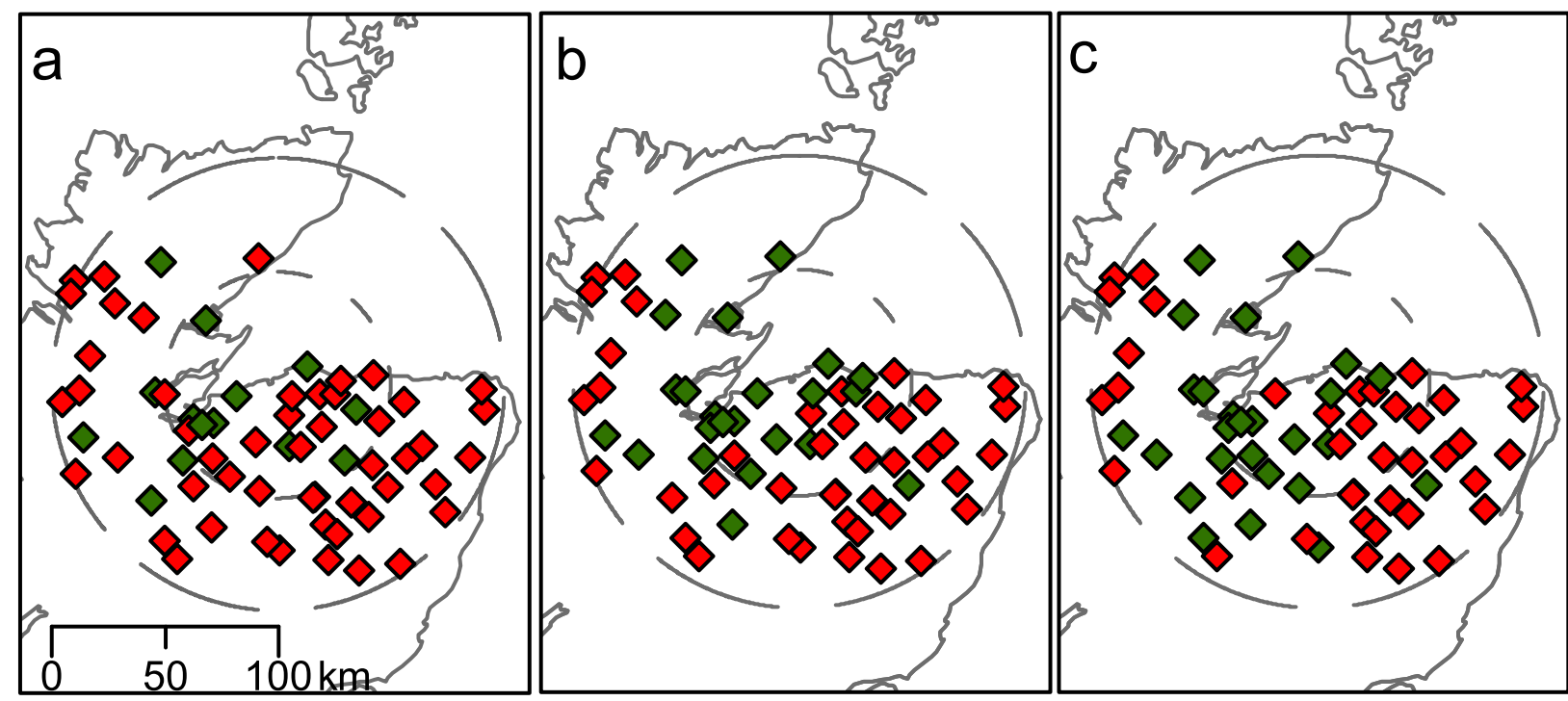

FIG. 8. Spatial plots indicating where the NXPol's dual-pol method (green) or the Nimrod (red) QPE performs best. Performance measures tested include (a) the absolute error, (b) bias, and (c) correlation to the rain gauge data. The inner and outer rings represent the $50-$ and $100-\mathrm{km}$ ranges, respectively.

We note that overall the examined QPE algorithms exhibit a negative bias in the hourly rainfall estimation. Throughout this study, the rainfall retrieval parameters are based on DSDs reported from other locations [i.e., Germany from Diederich et al. (2015a,b) and Oklahoma, United States, from Ryzhkov et al. (2014)]. If the DSDs observed in northern Scotland during the RAiNS campaign are skewed toward smaller raindrops this could explain the observed underestimation (Ryzhkov and Zrnić 2019). Such DSD dependencies were beyond the scope of this study but should be explored further in conjunction with the techniques discussed here as has been done for other locations by Ryzhkov and Zrnić (2019) and Cocks et al. (2019) using the newly acquired disdrometer and dual-polarization radar observations across the United Kingdom (Pickering et al. 2019). In addition to the error introduced by not accounting for local DSDs, the lack of VPR in this study, coupled with the orography in the region necessitating observations from higher elevations is also likely a cause of the negative bias. This is likely to be further enhanced by the lack of adjustment for orographic enhancement which is known to occur in this region (Harrison et al. 2000).

Even with the addition of dual-polarization capabilities there is no single solution to improving radar performance in this region. Where the complex orography allows observations to be obtained below the melting level there is a clear benefit to implementing QPEs derived from specific attenuation, although the exact parameterization could be improved as discussed above. In those regions where specific attenuation is not calculable (above the melting level and where radial differential phase shift is low) the results indicate QPEs utilizing $K_{\mathrm{dp}}$ outperform those that use only reflectivity (even when fully corrected). This is also likely to be the case during wintertime events and future work focused on the application of $K_{\mathrm{dp}}$ to ice phase QPEs is likely to significantly benefit this region. Further analysis is also required to determine the full spatial benefit of dual-polarization QPE methods, including performance testing using catchment-based hydrological models using different data sources to fully represent the challenges presented by this region.

Acknowledgments. Numerous people have provided assistance in the development and deployment of the NXPol. We thank them for their contributions and support in this effort. In particular, we thank Leonardo Germany GmbH for their excellent support and Mike Dixon of NCAR's Earth Observing Laboratory for his continued help in adapting LROSE to the needs of the NXPol. At Kinloss Barracks we thank Lieutenant Colonel Marc Wilson, Sergeant Rob Savage, Chris Sherwin, and William Ross for their logistical support during the RAiNS deployment. We thank Jim Sharp, Roger Kingham, Iain Thorburn, and Mark Walters from the U.K. Met Office at RAF Lossiemouth for their technical support throughout the campaign. The lead author would like to acknowledge the "Shut Up and Write" group in the School of Earth and Environment at the University of Leeds. Without the weekly space, time, and support this group offers, this manuscript would not have been written. The Natural Environment Research Council (NERC) Grant Hydro-JULES (NE/S017380/1) funded this work.

\section{REFERENCES}

Anagnostou, M. N., J. Kalogiros, E. N. Anagnostou, and A. Papadopoulos, 2009: Experimental results on rainfall estimation in complex terrain with a mobile X-band polarimetric weather radar. Atmos. Res., 94, 579-595, https:// doi.org/10.1016/j.atmosres.2009.07.009.

,,--- M. Tarolli, A. Papadopoulos, and M. Borga, 2010: Performance evaluation of high-resolution rainfall estimation by X-band dual-polarization radar for flash flood applications 
in mountainous basins. J. Hydrol., 394, 4-16, https://doi.org/ 10.1016/j.jhydrol.2010.06.026.

Andrieu, H., J. D. Creutin, G. Delrieu, and D. Faure, 1997: Use of a weather radar for the hydrology of a mountainous area. Part I: Radar measurement interpretation. J. Hydrol., 193, 1-25, https://doi.org/10.1016/S0022-1694(96)03202-7.

Antonini, A., S. Melani, M. Corongiu, S. Romanelli, A. Mazza, A. Ortolani, and B. Gozzini, 2017: On the implementation of a regional X-band weather radar network. Atmosphere, 8, 25, https://doi.org/10.3390/atmos8020025.

Bech, J., B. Codina, J. Lorente, and D. Bebbington, 2003: The sensitivity of single polarization weather radar beam blockage correction to variability in the vertical refractivity gradient. J. Atmos. Oceanic Technol., 20, 845-855, https://doi.org/10.1175/ 1520-0426(2003)020<0845:TSOSPW $>2.0 . \mathrm{CO} ; 2$.

Bechini, R., L. Baldini, and V. Chandrasekar, 2013: Polarimetric radar observations in the ice region of precipitating clouds at C-band and X-band radar frequencies. J. Appl. Meteor. Climatol., 52, 1147-1169, https://doi.org/10.1175/JAMC-D-12-055.1.

Bell, V. A., A. L. Kay, R. G. Jones, R. J. Moore, and N. S. Reynard, 2009: Use of soil data in a grid-based hydrological model to estimate spatial variation in changing flood risk across the UK. J. Hydrol., 377, 335-350, https://doi.org/ 10.1016/j.jhydrol.2009.08.031.

Bennett, L., 2019: RAiNS: NCAS mobile X-band radar scan data from Kinloss Barracks, Forres, Scotland, version 1. Centre for Environmental Data Analysis, accessed 26 February 2019, https://doi.org/10.5285/c86c0daa2e654beda74a79d17624f160.

Berne, A., and W. F. Krajewski, 2013: Radar for hydrology: Unfulfilled promise or unrecognized potential? Adv. Water Resour., 51, 357-366, https://doi.org/10.1016/j.advwatres.2012.05.005.

Bouilloud, L., G. Delrieu, B. Boudevillain, and P.-E. Kirstetter, 2010: Radar rainfall estimation in the context of post-event analysis of flash-flood events. J. Hydrol., 394, 17-27, https:// doi.org/10.1016/j.jhydrol.2010.02.035.

Brandes, E. A., A. V. Ryzhkov, and D. S. Zrnić 2001: An evaluation of radar rainfall estimates from specific differential phase, J. Atmos. Oceanic Technol., 18: 363-375, https://doi.org/10.1175/ 1520-0426(2001)018\%3C0363:AEORRE\%3E2.0.CO;2.

Bringi, V. N., and V. Chandrasekar, 2001: Polarimetric Doppler Weather Radar: Principles and Applications. Cambridge University Press, 636 pp.

Campbell Scientific Europe, 2018: SBS500 Coated Aluminium Tipping Bucket Raingauge. Accessed 25 July 2018, https:// www.campbellsci.co.uk/sbs500.

Ciach, G. J., 2003: Local random errors in tipping-bucket rain gauge measurements. J. Atmos. Oceanic Technol., 20, 752-759, https://doi.org/10.1175/1520-0426(2003)20<752: LREITB $>2.0 . \mathrm{CO} ; 2$.

—_, and W. F. Krajewski 1999: Radar-rain gauge comparisons under observational uncertainties. J. Appl. Meteor., 38, 1519-1525, https://doi.org/10.1175/1520-0450(1999)038\%3C1519: RRGCUO\%3E2.0.CO;2.

Cifelli, R., and V. Chandrasekar, 2010: Dual-Polarization Radar Rainfall Estimation. Rainfall: State of the Science, Geophys. Monogr., Vol. 191, Amer. Geophys. Union, 105-125, https:// doi.org/10.1029/2010GM000930.

, - S. Lim, P. C. Kennedy, Y. Wang, and S. A. Rutledge, 2011: A new dual-polarization radar rainfall algorithm: Application in Colorado precipitation events. J. Atmos. Oceanic Technol., 28, 352-364, https://doi.org/10.1175/2010JTECHA1488.1.

Cocks, S. B., and Coauthors, 2019: A prototype quantitative precipitation estimation algorithm for operational S-band polarimetric radar utilizing specific attenuation and specific differential phase. Part II: Performance verification and case study analysis. J. Hydrometeor., 20, 999-1014, https://doi.org/ 10.1175/JHM-D-18-0070.1.

Cole, S. J., and R. J. Moore, 2009: Distributed hydrological modelling using weather radar in gauged and ungauged basins. Adv. Water Resour., 32, 1107-1120, https://doi.org/10.1016/ j.advwatres.2009.01.006.

Creutin, J. D., H. Andrieu, and D. Faure, 1997: Use of a weather radar for the hydrology of a mountainous area. Part II: Radar measurement validation. J. Hydrol., 193, 26-44, https:// doi.org/10.1016/S0022-1694(96)03203-9.

Darlington, T., and Coauthors, 2016: Designing an operational $\mathrm{C}$-band radar to realise the benefits of dual-polarization. Met Office, 48 pp., https://digital.nmla.metoffice.gov.uk/download/ file/IO_2d8307eb-dfb4-4d6e-8ead-4df70259325e.

Diederich, M., A. Ryzhkov, C. Simmer, P. Zhang, and S. Trömel, 2015a: Use of specific attenuation for rainfall measurement at $\mathrm{X}$-band radar wavelengths. Part I: Radar calibration and partial beam blockage estimation. J. Hydrometeor., 16, 487-502, https:// doi.org/10.1175/JHM-D-14-0066.1.

$\ldots, \ldots, \ldots, \ldots$, and ——, 2015b: Use of specific attenuation for rainfall measurement at X-band radar wavelengths. Part II: Rainfall estimates and comparison with rain gauges. J. Hydrometeor., 16, 503-516, https://doi.org/ 10.1175/JHM-D-14-0067.1.

Dufton, D. R. L., 2016: Quantifying uncertainty in radar rainfall estimates using an $\mathrm{X}$-band dual polarisation weather radar. Ph.D. thesis, University of Leeds, 207 pp., http://etheses. whiterose.ac.uk/15486/.

— , and C. G. Collier, 2015: Fuzzy logic filtering of radar reflectivity to remove non-meteorological echoes using dual polarization radar moments. Atmos. Meas. Tech., 8, 3985-4000, https:// doi.org/10.5194/amt-8-3985-2015.

Fabry, F., 2015: Radar Meteorology: Principles and Practice. Cambridge University Press, 256 pp., https://doi.org/10.1017/ CBO9781107707405.

— , and I. Zawadzki, 1995: Long-term radar observations of the melting layer of precipitation and their interpretation. J. Atmos. Sci., 52, 838-851, https://doi.org/10.1175/1520-0469(1995) 052<0838:LTROOT $>2.0$. CO;2.

Germann, U., G. Galli, M. Boscacci, and M. Bolliger, 2006: Radar precipitation measurement in a mountainous region. Quart. J. Roy. Meteor. Soc. 132, 1669-1692, https://doi.org/10.1256/qj.05.190.

Giuli, D., M. Gherardelli, A. Freni, T. A. Seliga, and K. Aydin, 1991: Rainfall and clutter discrimination by means of dual-linear polarization radar measurements. J. Atmos. Oceanic Technol., 8, 777-789, https://doi.org/10.1175/1520-0426(1991) $008<0777:$ RACDBM $>2.0 . \mathrm{CO} ; 2$.

Golding, B. W., 1998: Nimrod: A system for generating automated very short range forecasts. Met. Apps, 5 (1), 1-16, https:// doi.org/10.1017/S1350482798000577.

Gourley, J. J., A. J. Illingworth, and P. Tabary, 2009: Absolute calibration of radar reflectivity using redundancy of the polarization observations and implied constraints on drop shapes. J. Atmos. Oceanic Technol., 26, 689-703, https:// doi.org/10.1175/2008JTECHA1152.1.

, S. E. Giangrande, Y. Hong, Z. L. Flamig, T. Schuur, and J. A. Vrugt, 2010: Impacts of polarimetric radar observations on hydrologic simulation. J. Hydrometeor., 11, 781-796, https:// doi.org/10.1175/2010JHM1218.1.

Hall, W., M. A. Rico-Ramirez, and S. Krämer, 2015: Classification and correction of the bright band using an operational C-band 
polarimetric radar. J. Hydrol., 531, 248-258, https://doi.org/ 10.1016/j.jhydrol.2015.06.011.

Harrison, D. L., S. J. Driscoll, and M. Kitchen, 2000: Improving precipitation estimates from weather radar using quality control and correction techniques. Meteor. Appl., 7, 135-144, https://doi.org/10.1017/S1350482700001468.

- , K. Norman, C. Pierce, and N. Gaussiat, 2012: Radar products for hydrological applications in the UK. Water Manage., 165, 89-103, https://doi.org/10.1680/wama.2012.165.2.89.

Heistermann, M., S. Jacobi, and T. Pfaff, 2013: An open source library for processing weather radar data (wradlib). Hydrol. Earth Syst. Sci., 17, 863-871, https://doi.org/10.5194/hess-17863-2013.

Herzegh, P. H., and A. R. Jameson, 1992: Observing precipitation through dual-polarization radar measurements. Bull. Amer. Meteor. Soc., 73, 1365-1374, https://doi.org/10.1175/ 1520-0477(1992)073<1365:OPTDPR > 2.0.CO;2.

Holleman, I., D. Michelson, G. Galli, U. Germann, M. Peura, and H. Hohti, 2006: Quality information for radars and radar data. OPERA work package 1.2, accessed 26 February 2019, http://opera.radar.tugraz.at/docum/opera_2/OPERA_2005_ 19_DataQuality.pdf.

Hu, Z., L. Liu, L. Wu, and Q. Wei, 2015: A comparison of denoising methods for differential phase shift and associated rainfall estimation. J. Meteor. Res., 29, 315-327, https://doi.org/ 10.1007/s13351-015-4062-6.

Hubbert, J. C., M. Dixon, and S. M. Ellis, 2009: Weather radar ground clutter. Part II: Real-time identification and filtering. J. Atmos. Oceanic Technol., 26, 1181-1197, https://doi.org/ 10.1175/2009JTECHA1160.1.

Kendon, M., M. McCarthy, S. Jevrejeva, A. Matthews, and T. Legg, 2018: State of the UK climate. Int. J. Climatol., 38, 1-35, https:// doi.org/10.1002/joc.5798.

Kidd, C., and A. Becker, G. J. Huffman, C. L. Muller, P. Joe, G. Skofronick-Jackson, and D. B. Kirschbaum, 2017: So, how much of the Earth's surface is covered by rain gauges? Bull. Amer. Meteor. Soc., 98, 69-78, https://doi.org/10.1175/ BAMS-D-14-00283.1.

Kumjian, M., 2013: Principles and applications of dual-polarization weather radar. Part III: Artifacts. J. Operat. Meteor., 1, 265-274, https://doi.org/10.15191/nwajom.2013.0121.

Lakshmanan, V., C. Karstens, J. Krause, and L. Tang, 2014: Quality control of weather radar data using polarimetric variables. J. Atmos. Oceanic Technol., 31, 1234-1249, https://doi.org/ 10.1175/JTECH-D-13-00073.1.

Lascaux, F., E. Richard, and J.-P. Pinty, 2007: Numerical simulations of three different MAP IOPs and the associated microphysical processes. Quart. J. Roy. Meteor. Soc., 132, 1907-1926, https://doi.org/10.1256/qj.05.197.

Liu, H., and V. Chandrasekar, 2000: Classification of hydrometeors based on polarimetric radar measurements: Development of fuzzy logic and neuro-fuzzy systems, and in situ verification. J. Atmos. Oceanic Technol., 17, 140-164, https://doi.org/10.1175/1520-0426(2000)017<0140:COHBOP> 2.0.CO;2.

Marshall, J. S., and W. Palmer, 1948: The distribution of raindrops with size. J. Meteor., 5, 165-166, https://doi.org/ 10.1175/1520-0469(1948)005<0165:TDORWS > 2.0.CO;2.

—_, W. Hitschfeld, and K. Gunn, 1955: Advances in weather radar. Adv. Geophys., 2, 1-56, https://doi.org/10.1016/S00652687(08)60310-6.

Matrosov, S. Y., D. E. Kingsmill, B. E. Martner, and F. M. Ralph, 2005: The utility of X-band polarimetric radar for quantitative estimates of rainfall parameters. J. Hydrometeor., 6, 248-262, https://doi.org/10.1175/JHM424.1.

Met Office, 2003: Met Office Rain Radar Data from the NIMROD System. NCAS British Atmospheric Data Centre, accessed 14 March 2018, http://catalogue.ceda.ac.uk/uuid/ 82adec1f896af6169112d09cc1174499.

_ 2018: UK climate averages. Met Office accessed 31 December 2020, https://www.metoffice.gov.uk/research/climate/mapsand-data/uk-climate-averages.

Moore, R. J., S. J. Cole, V. A. Bell, and D. A. Jones, 2006: Issues in flood forecasting: Ungauged basins, extreme floods and uncertainty. IAHS Publ., 305, 103-122.

Neely, R. R., III, and Coauthors, 2018: The NCAS mobile dual-polarisation Doppler X-band weather radar (NXPol). Atmos. Meas. Tech., 11, 6481-6494, https://doi.org/10.5194/ amt-11-6481-2018.

Ogden, F. L., H. O. Sharif, S. U. S. Senarath, J. A. Smith, M. L. Baeck, and J. R. Richardson, 2000: Hydrologic analysis of the Fort Collins, Colorado, flash flood of 1997. J. Hydrol., 228, 82-100, https://doi.org/10.1016/S0022-1694(00)00146-3.

Pellarin, T., G. Delrieu, G.-M. Saulnier, H. Andrieu, B. Vignal, and J.-D. Creutin, 2002: Hydrologic visibility of weather radar systems operating in mountainous regions: Case study for the Ardèche catchment (France). J. Hydrometeor., 3, 539-555, https://doi.org/10.1175/1525-7541(2002)003<0539:HVOWRS > 2.0.CO;2.

Picca, J. C., D. M. Schultz, B. A. Colle, S. Ganetis, D. R. Novak, and M. J. Sienkiewicz, 2014: The value of dual-polarization radar in diagnosing the complex microphysical evolution of an intense snowband. Bull. Amer. Meteor. Soc., 95, 1825-1834, https://doi.org/10.1175/BAMS-D-13-00258.1.

Pickering, B. S., R. R. Neely III, and D. Harrison, 2019: The Disdrometer Verification Network (DiVeN): A UK network of laser precipitation instruments. Atmos. Meas. Tech., 12, 5845-5861, https://doi.org/10.5194/amt-12-58452019.

Rico-Ramirez, M. A., and I. D. Cluckie, 2008: Classification of ground clutter and anomalous propagation using dualpolarization weather radar. IEEE Trans. Geosci. Remote Sens., 46, 1892-1904, https://doi.org/10.1109/TGRS.2008.916979.

- — - and D. Han, 2005: Correction of the bright band using dual-polarisation radar. Atmos. Sci. Lett., 6, 40-46, https:// doi.org/10.1002/asl.89.

Ryzhkov, A. V., and D. S. Zrnić, 2019: Radar Polarimetry for Weather Observations. Springer, 486 pp.

- M. Diederich, P. Zhang, and C. Simmer, 2014: Potential utilization of specific attenuation for rainfall estimation, mitigation of partial beam blockage, and radar networking. J. Atmos. Oceanic Technol., 31, 599-619, https://doi.org/ 10.1175/JTECH-D-13-00038.1.

Shakti, P. C., M. Maki, S. Shimizu, T. Maesaka, D. S. Kim, D. I. Lee, and H. Iida, 2013: Correction of reflectivity in the presence of partial beam blockage over a mountainous region using $\mathrm{X}$-band dual polarization radar. J. Hydrometeor., 14, 744-764, https://doi.org/10.1175/JHM-D-12-077.1.

Straka, J. M., D. S. Zrnić, and A. V. Ryzhkov, 2000: Bulk hydrometeor classification and quantification using polarimetric radar data: Synthesis of relations. J. Appl. Meteor., 39, 1341-1372, https://doi.org/10.1175/1520-0450(2000)039<1341: BHCAQU $>2.0 . \mathrm{CO} ; 2$.

Tabary, P., A. A. Boumahmoud, H. Andrieu, R. J. Thompson, A. J. Illingworth, E. L. Bourar, and J. Testud, 2011: Evaluation of two "integrated" polarimetric quantitative precipitation 
estimation (QPE) algorithms at C-band. J. Hydrol., 405, 248260, https://doi.org/10.1016/j.jhydrol.2011.05.021

Testud, J., E. Le Bouar, E. Obligis, and M. Ali-Mehenni, 2000: The rain profiling algorithm applied to polarimetric weather radar. J. Atmos. Oceanic Technol., 17, 332-356, https://doi.org/ 10.1175/1520-0426(2000)017<0332:TRPAAT>2.0.CO;2.

Torres, S. M., and D. S. Zrnić, 1999: Ground clutter canceling with a regression filter. J. Atmos. Oceanic Technol., 16, 1364-1372, https://doi.org/10.1175/1520-0426(1999)016<1364:GCCWAR> 2.0.CO;2.

Vulpiani, G., M. Montopoli, L. D. Passeri, A. G. Gioia, P. Giordano, and F. S. Marzano, 2012: On the use of dualpolarized C-band radar for operational rainfall retrieval in mountainous areas. J. Appl. Meteor. Climatol., 51, 405-425, https://doi.org/10.1175/JAMC-D-10-05024.1.

Wang, Y., and V. Chandrasekar, 2009: Algorithm for estimation of the specific differential phase. J. Atmos. Oceanic Technol., 26, 2565-2578, https://doi.org/10.1175/2009JTECHA1358.1.

— the CASA X-band dual-polarization radar network. J. Atmos. Oceanic Technol., 27, 1665-1676, https://doi.org/10.1175/ 2010JTECHA1419.1.

Zrnić, D. S., and A. V. Ryzhkov, 1999: Polarimetry for weather surveillance radars. Bull. Amer. Meteor. Soc., 80, 389-406, https://doi.org/10.1175/1520-0477(1999)080<0389:PFWSR > 2.0.CO;2. 